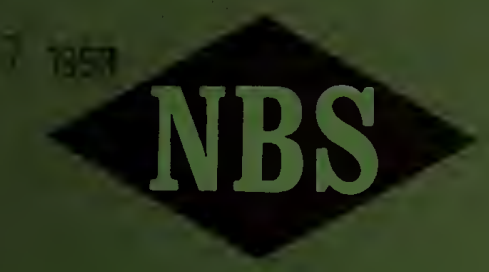

\title{
TECHNICAL
}

NOTE

\section{Misalinement Detector for Axial Loading Fatigue Machines}

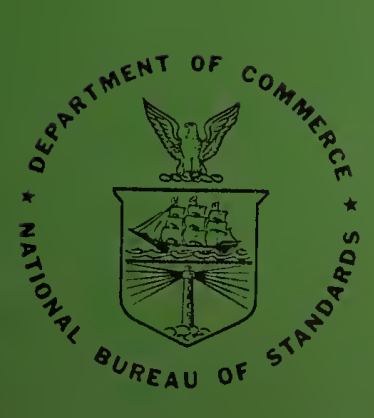

U.S. DEPARTMENT OF COMMERCE National Bureau of Standards 



\title{
UNITED STATES DEPARTMENT OF COMMERCE \\ Maurice H. Stans, Secretary
}

NATIONAL BUREAU OF STANDARDS - A. V. Astin, Director

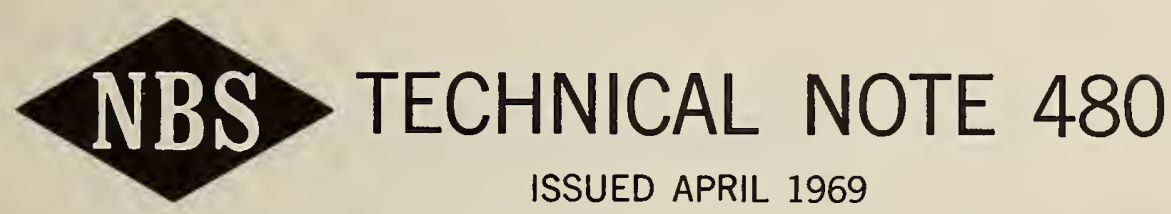

\section{Misalinement Detector for Axial Loading Fatigue Machines}

Donald C. Robinson

\author{
Engineering Mechanics Section \\ Mechanics Division \\ Institute for Basic Standards \\ National Bureau of Standards \\ Washington, D.C. 20234
}

NBS Technical Notes are designed to supplement the Bureau's regular publications program. They provide a means for making available scientific data that are of transient or limited interest. Technical Notes may be listed or referred to in the open literature. 
Contents

Page

Abstract $-\ldots--\ldots-\ldots-\ldots-\ldots$

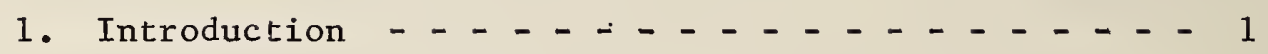

2. Misalinement Detector Design - - - - - - - - 2

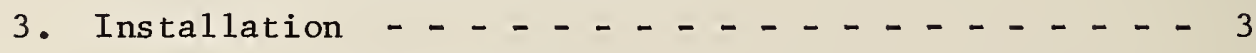

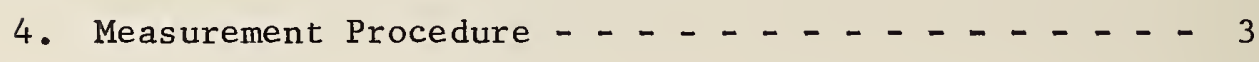

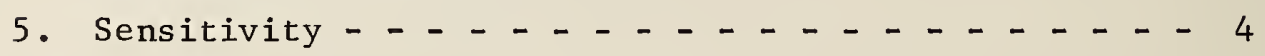

6. Results and Discussion $-{ }_{-}-{ }_{-}-{ }_{-}-{ }_{-}-{ }_{-} 4$

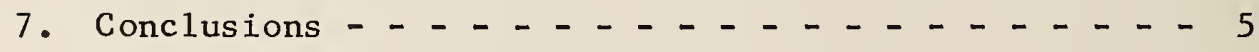

8. References $--\ldots-\ldots-\ldots--\ldots$ 
by Donald C. Robinson

\section{ABSTRACT}

A strain gage device for measuring changes in alinement between the test fixtures of axial loading fatigue machines is described. Variations in fixture orientation are determined by measurement of the bending induced in a compliant beam clamped in parallel mounts attached to the test fixtures. Changes in bending with applied tension loads are an indication of alterations in the alinement between the load transmitting members of a machine. An approximately linear relationship was found to exist between changes in bending determined by the detector and the fatigue life of high strength fasteners for various levels of misalinement induced in a fatigue machine.

Key words: Axial loading, fatigue machine, misalinement, test fixtures.

\section{Introduction}

In order for a fatigue testing machine to give significant results, it must produce the desired stress distribution within the specimen. Fatigue lives of high strength metal fasteners, for example, have shown large variations in tension-tension tests due to the presence of undesired bending loads*. For the quality control of such products, it is necessary to detect undesired stresses due to misalinement of the testing machine in order to determine when variations in the test results are due to an inferior lot rather than due to the machine. This note describes the development of a device for detecting such misalinement。

Various methods have been used by other investigators for minimizing misalinement in a fatigue machine. Some require precision machining of specimens and the machine test fixtures[1]**. Othar

\footnotetext{
$\%$

Personal Communications with the Engineering Staff of the Precision

Fastener Division, Standard Pressed Steel Company, Jenkintown, ** Pennsylvania.

Numbers in brackets indicate the literature references at the end of this paper.
} 
alining procedures have been developed in which a misalinement indicating device is installed in a machine in place of, or in series with, a specimen. This technique allows the possibility of a change in alinement when the device is removed. The device described in this report is able to detect misalinement of the load transmitting members of an axial-loading machine for the range of loads applied during a tension-tension test while a specimen remains in place. Changes in the alinement of the machine are indicated by bending induced in the detector which is attached to the machine test fixtures.

\section{Misalinement Detector Design}

A schematic of the misalinement detector is shown in Figure 1. Its prircipal components are a beam, a flexure, and fittings for attaching the detector to fatigue test fixtures. The beam was constructed from an 11 in. $(279.4 \mathrm{~mm}) \times 1$ in. $(25.4 \mathrm{~mm}) \times 3 / 16$ in. $(4.8$ $\mathrm{mm})$ aluminum bar. The center portion of this member was reduced to approximately $0.625 \times 0.016$ in. $(15.9 \times 0.4 \mathrm{~mm})$. A four-arm, temperature compensated bridge circuit constructed of foil-type, resistance strain gages was bonded to the reduced section. It was connected to measure bending and to cancel axial strain components.

The purpose of the flexure was to transmit the effects of bending due to misalined test fixtures to the gaged section of the beam. It was required that the flexure have a low resistance to axial motion and also provide for a connection to the test fixture surfaces having high stiffness in the horizontal direction. A leaf flexure, whose basic operating principle is given by Jones and Young[2], was employed. A cross section through the flexure is shown in Figure 1 . The flexure leaves were constructed from $0.005 \mathrm{in}$. $(0.13 \mathrm{~mm})$ brass shims arranged to provide parallel motion of a rectangular element having a 0.281 in. ${ }^{2}\left(7.1 \mathrm{~mm}^{2}\right)$ surface area which was in contact with the surface of the beam. Polytetrafluoroethylene tape was applied to each of these surfaces and to the end of the beam to minimize the friction due to sliding.

The flexure was used to clamp the upper end of the beam to a steel fitting, and the lower end of the beam was bolted to another fitting. Both fittings were clamped to the circumference of the test fixtures by means of an adjustable metal clamp. In order to minimize the misalinement between the pair of fittings themselves, they were fabricated from one piece of material and cut along a plane perpendicular to the mounting surfaces during the last machining operation. Although these fittings were designed for cylindrical test fixtures, fittings for attaching to other fixtures are feasible.

In order to protect the compliant gaged section of the beam from being damaged during assembly, cover plates which attach to the beam by screws completely enclosed the reduction section. It was necessary to loosen these plates when the detector was being used in order for 
bending of the beam due to misalinement between its mounting surfaces to be effectively transmitted to the strain gages.

In order to obtain an absolute determination of misalinement, the test fixtures could be compared to a precision alined surface external to a testing machine. Due to the beam configuration and gage arrangement, it is difficult to prevent the beam from transmitting undesired torsional strains to the compliant gaged section which would be misinterpreted as due to bending. This device measures bending in only one plane. In this investigation, care was taken to aline this plane with the plane of bending.

\section{Installation}

To minimize any misalinement between the fittings which attach the beam to the machine test fixtures, a uniform steel fitting alinement bar, having the same nominal size as the gaged beam, is first clamped to the fittings. The adjustable clamps which fasten the fittings to the test fixtures are then tightened, the alinement bar is removed and the gaged beam is installed.

One end of the beam is fastened to the upper fitting by means of the flexure, and its other end is fastened to the lower fitting by screws, as shown in Figure 1. To insure that the bearing surface of the flexure is in uniform contact with the beam, the upper end of the beam is first connected, the screws attaching the plates covering the gaged section are loosened and the lower end of the member is then tightened.

\section{Measurement Procedure}

The bending determined by the detector, which is an indication of the bending transmitted between the fatigue test fixtures to the specimen is measured using a strain indicator. The procedure for estimating the change in alinement between test fixtures over the range of loads applied during a tension-tension fatigue test is as follows :

1. Apply a static tension load to a specimen corresponding to the mean cyclic load.

2. Balance the strain gage bridge.

3. Reduce the load to a value corresponding to the minimum cyclic load, rebalance the bridge, and record the indicated strain.

4. Remove the misalinement detector before beginning a fatigue test. 
A calibration of the misalinement detector which was used to estimate its sensitivity was determined by recording the bending at its gaged section induced by various size shims placed under one of the attachment fittings while the detector was clamped to a uniform cylindrical surface. The calibration curve shown in Figure 2 was determined by placing shims under one fitting located approximately 5.0 in. $(127 \mathrm{~mm})$ from the gaged section while the other end of the beam was clamped. From these data, it is estimated that the detector is capable of determining bending less than one percent of the axial strain experienced by a $1 / 4$ in. ( $6 \mathrm{~mm}$ ) diameter specimen when subjected to a tension load. When the detector is attached to the test fixtures of a machine, its sensitivity is also influenced by the rigidity of the machine.

\section{Results and Discussion}

In order to verify that the bending determined by the detector was representative of the bending experienced by a specimen, a strain gage bridge circuit for measuring bending was bonded to the surface of a $1 / 4$ in. (6 mm) diameter bolt. A comparison of the bending in a bolt with the bending determined by the misalinement detector, shown in Figure 3, was found by attaching the detector to $3 \mathrm{in.} \mathrm{(76} \mathrm{mm)} \mathrm{dia-}$ meter test fixtures installed in a 5,000 lbf (22,000 N) capacity, hydraulic, axial loading fatigue machine. The data plotted in Figure 3 shows two regions, represented by dashed and solid lines. The portion of the curves which are dashed indicates a region where the detector measured bending before the bolt was tightly seated in the test fixtures. After the fastener was seated, the region represented by solid lines, the coefficient of correlation for the two sets of data was 0.95 . This indicates that the bending experienced by the two correlate linearly.

Another investigation was made in which misalinement was induced in a fatigue machine with beveled washers. The washers, whose flat surfaces were ground non-parallel, were placed under the bolt heads of $1 / 4$ in. (6 mm) diameter stee1 fasteners. A 24,000 1bf $(107,000 \mathrm{~N})$ capacity, electromechanical, axial loading machine was used. The test fixtures were $21 / 2$ in. $(64 \mathrm{~mm})$ in diameter.

The values of bending induced by washers with various angles at tension loads of $2,000 \operatorname{lbf}(8,900 \mathrm{~N}), 1,000 \operatorname{lbf}(4,450 \mathrm{~N})$ and $2001 \mathrm{bf}$ $(890 \mathrm{~N})$ are given in Table 1 . The results of fatigue tests on the same bolts are given in Table 2. These fasteners have an assembly minimum tensile strength of $260,000 \mathrm{lbf} / \mathrm{in} .2\left(1,790 \mathrm{MN} / \mathrm{m}^{2}\right)$, and were known to be particularly sensitive to bending loads when subjected to tension-tension fatigue tests. The curves in Figure 4 give the comparison of the data from Table 1 for a tension load of 200 lbf $(890 \mathrm{~N})$ and the average fatigue life of the bolts. The bending was measured at $200 \mathrm{Ibf}(890 \mathrm{~N})$ to determine whether the test fixture 
alinement changed significantly below the minimum load applied during the fatigue tests. The data did not indicate any large changes in fixture alinement for the two loads within the range of the fatigue test and the alinement for the load below the test range. The data for a tension load of $200 \mathrm{lbf}(890 \mathrm{~N})$ was used for comparison with the average fatigue life of the bolts since the larger scatter in the measurements at $2,000 \mathrm{lbf}(8,900 \mathrm{~N})$ and $1,0001 \mathrm{bf}(4,450 \mathrm{~N})$ suggests that the orientation of the larger washers below the bolt heads was more critical at the larger, loads and this orientation was not closely controlled. The questionable data are identified in Table 1 .

The values for the fatigue life of the $1 / 4 \mathrm{in} .(6 \mathrm{~mm})$ diameter bolts and the bending determined by the misalinement detector when the fixtures were alined ( 0 degree washer) were most affected by the smallest angularity induced by the beveled washers, 0.18 degree, with relatively smaller changes being observed for larger angularities up to 1.1 degrees. The magnitude of the coefficient of correlation[3] between the bending determined at $200 \mathrm{lbf}(890 \mathrm{~N})$ and the fatigue life for various washers was approximately 0.9 ; in Figure 5 is shown a direct comparison of the bending at this load and the average fatigue life of the bolts.

\section{Conclusions}

The device described in this report utilizes bending induced in a compliant beam to detect changes in the alinement of the test fixtures of an axial loading fatigue machine for a range of loads applied during a tension-tension test. The changes in bending with applied load are an indication of alterations in the alinement of the load transmitting members, which should be kept to a minimum to prevent excessive bending loads from being applied to a specimen.

Based on the experimental measurements, the relationship between the bending determined by the detector due to misalined test fixtures and bending experienced by a specimen installed in the fixtures was linear. An approximately linear relationship was found to exist between the bending determined by the detector and the fatigue life of high strength bolts for various levels of misalinement induced in a fatigue machine.

Mr。R. Snyder assisted in the construction of the misalinement detector. Mr。T. Baumgartner, Engineering Manager of the Precision Fastener Division, Standard Pressed Steel Company, Jenkintown, Pennsylvania, arranged for tests to be conducted on fatigue equipment at the Jenkintown plant. 
The project which led to this report was conducted under the sponsorship and with the financial assistance of the Naval Air Systems Command, Department of the Navy.

\section{References}

1. Weibull, W., Fatigue Testing and Analysis of Results, Pergamon Press (1961).

2. Jones, R. V。 and Young, I. R., Some Parasitic Deflexions in Parallel Spring Movements, J. Sci. Instr., 33, p. 11-15 (Jan. 1956).

3. Li, J. C. R., Statistical Inference, Vol. I, p. 301, Edwards Brothers, Inc., (1964). 
Table 1 - Strain Indicated by the Misalinement Detector Due To Beveled Washers Installed in an Electromechanical Testing Machine (a)

\begin{tabular}{|c|c|c|c|}
\hline & \multicolumn{3}{|c|}{ Applied tension loads } \\
\hline $\begin{array}{r}\text { Angle of } \\
\text { beveled washer }\end{array}$ & $\begin{array}{l}20001 \mathrm{bf} \\
(8900 \mathrm{~N}) \\
\end{array}$ & $\begin{array}{l}10001 \mathrm{bf} \\
(4450 \mathrm{~N})\end{array}$ & $\begin{array}{l}2001 \mathrm{bf} \\
(890 \mathrm{~N})\end{array}$ \\
\hline deg & in./in. & in./in. & in./in. \\
\hline 0 & $58 \times 10^{-6}$ & $69 \times 10^{-6}$ & $85 \times 10^{-6}$ \\
\hline 0.18 & 144 & 160 & 166 \\
\hline 0.41 & 176 & 175 & 177 \\
\hline 0.62 & 149 (b) & $162^{(b)}$ & 176 \\
\hline 0.93 & $228^{(b)}$ & 223 (b) & 180 \\
\hline 1.08 & $238^{(b)}$ & $242^{(b)}$ & 215 \\
\hline
\end{tabular}

(a) These values represent changes in bending found at a load of $2500 \mathrm{lbf}(11,120 \mathrm{~N})$ and the indicated load.

(b) Questionable data due to orientation of beveled washers. 
Table 2 - Effect of Angularity of Bolt Head Seat on the Fatigue Life of $1 / 4$ inch $(6 \mathrm{~mm})$ Diameter Fasteners. TensionTension Load Cycles of 505 to 5050 lbf (2250 to $22,500 \mathrm{~N})$

(a)

\begin{tabular}{|c|c|c|c|}
\hline $\begin{array}{r}\text { Angle of } \\
\text { beveled washer }\end{array}$ & $\begin{array}{l}\text { Cycles } \\
\text { to failure }\end{array}$ & $\begin{array}{l}\text { Average } \\
\text { fatigue life }\end{array}$ & $\begin{array}{c}\text { Average reduction } \\
\text { in fatigue life }\end{array}$ \\
\hline $\mathrm{deg}$ & & cycles & percent \\
\hline 0 & $\begin{array}{r}126,000 \\
78,000\end{array}$ & 102,000 & 0 \\
\hline 0.18 & $\begin{array}{l}53,000 \\
39,000 \\
85,000 \\
73,000\end{array}$ & 62,500 & 39 \\
\hline 0.41 & $\begin{array}{l}66,000 \\
34,000 \\
28,000 \\
43,000\end{array}$ & 42,750 & 58 \\
\hline 0.62 & $\begin{array}{l}45,000 \\
46,000 \\
36,000 \\
42,000\end{array}$ & 42,250 & 59 \\
\hline 0.93 & $\begin{array}{l}56,000 \\
42,000\end{array}$ & 49,000 & 52 \\
\hline 1.08 & $\begin{array}{l}44,000 \\
32,000\end{array}$ & 38,000 & 63 \\
\hline
\end{tabular}

(a) Axial stress levels corresponding to this loading were 10,300 to $103,0001 \mathrm{bf} / \mathrm{in} .^{2}$ ( 71 to $710 \mathrm{MN} / \mathrm{m}^{2}$ ). 

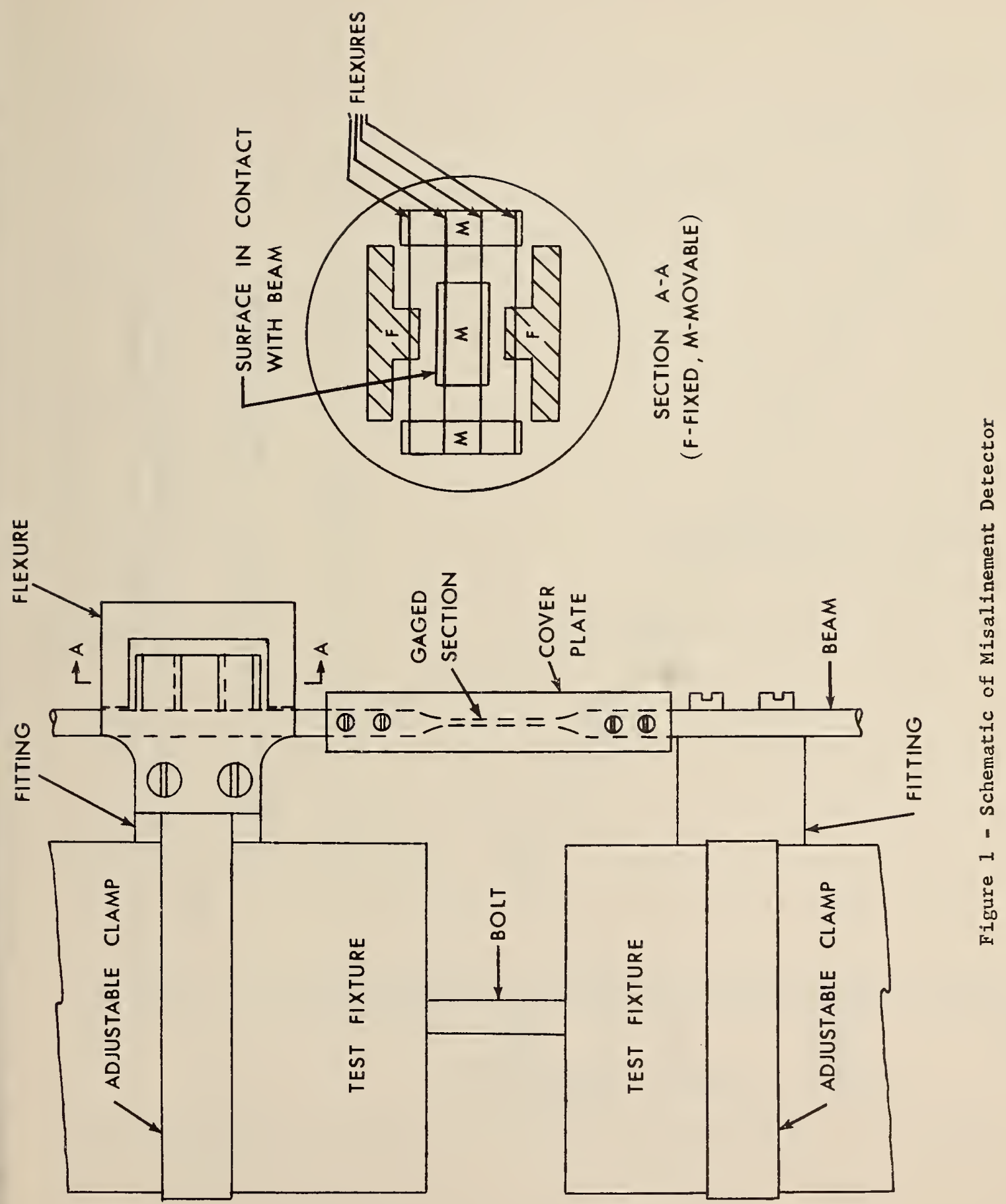


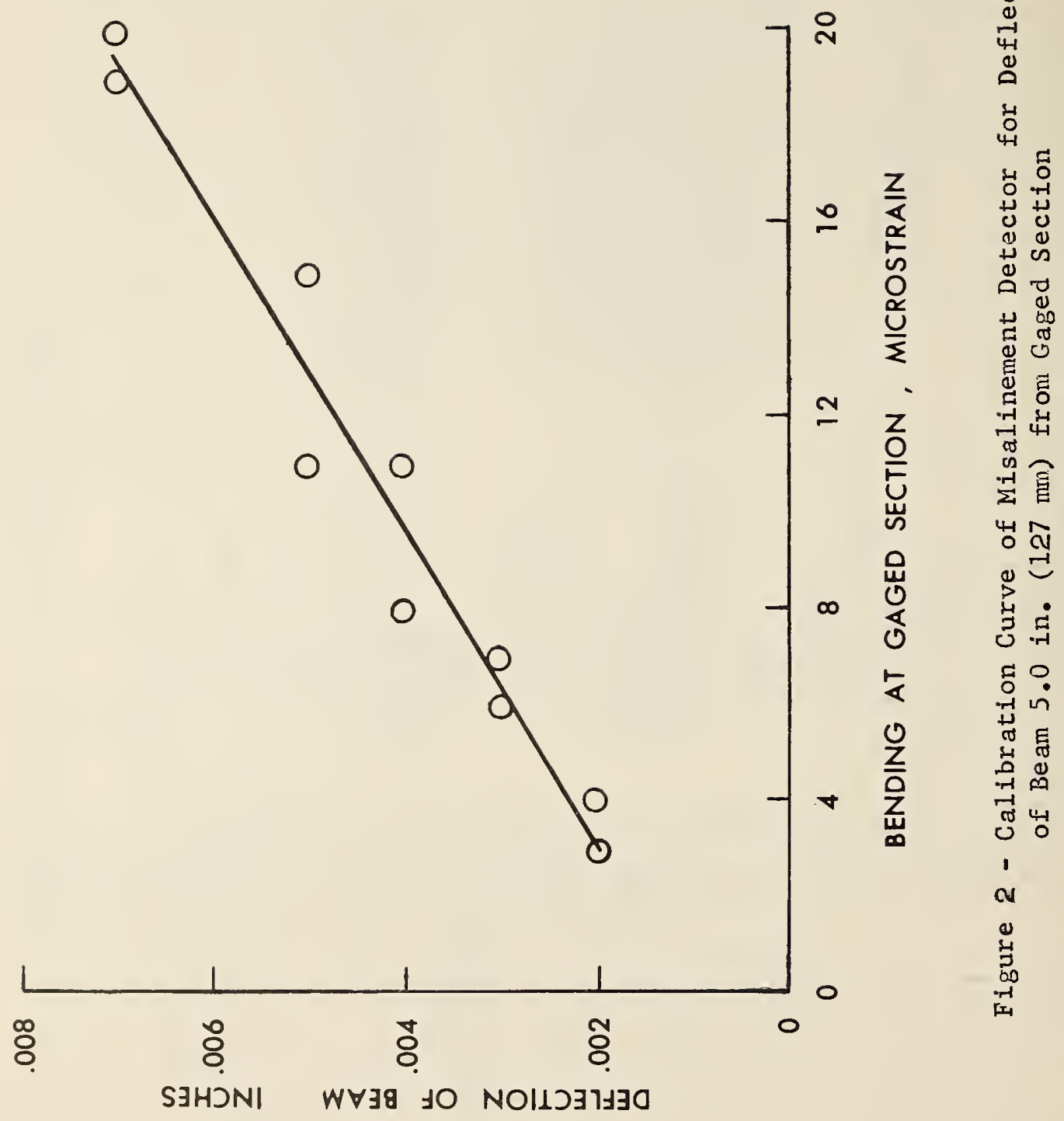




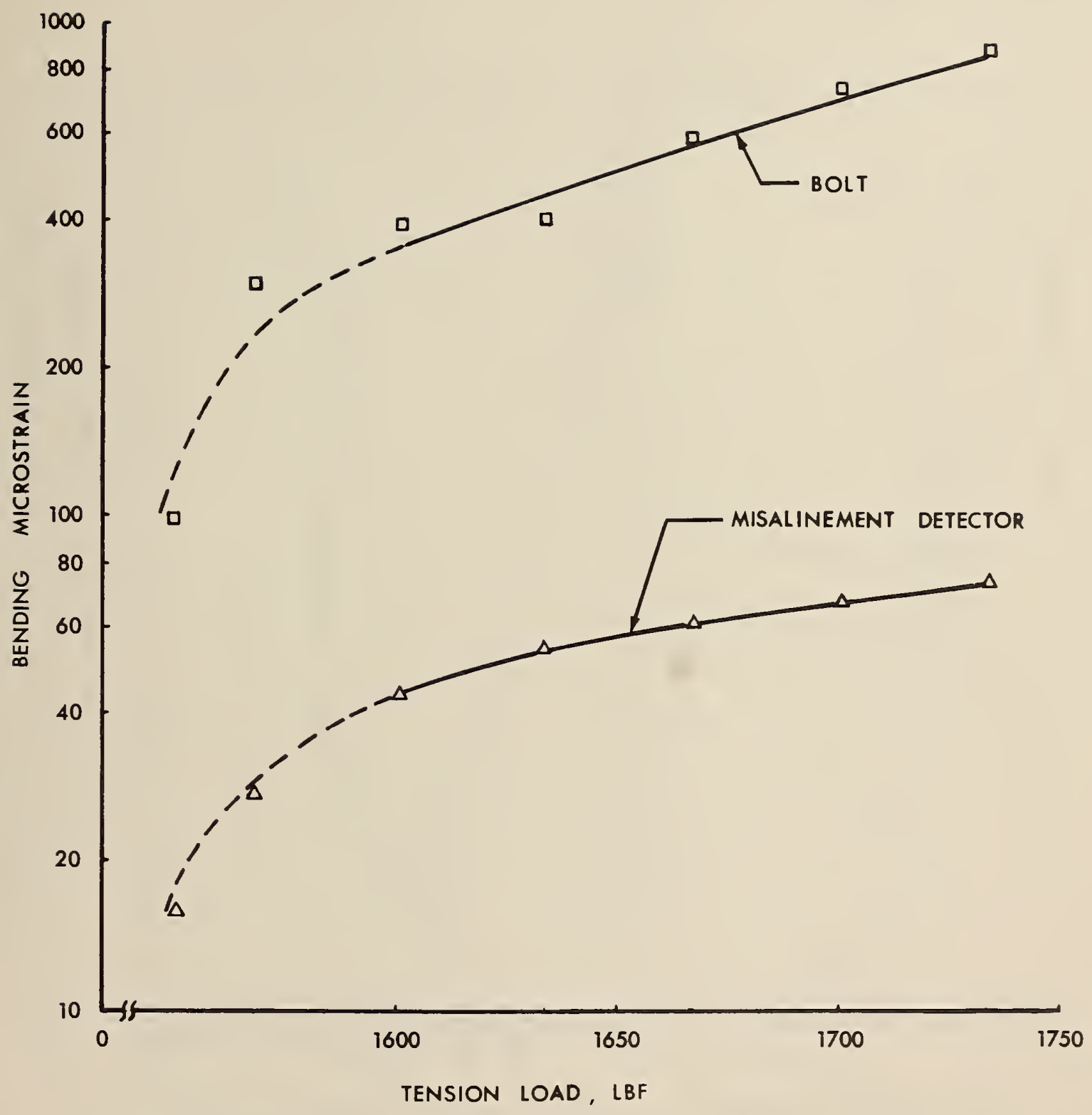

Figure - Comparison of Bending in a Bolt with Bending Determined by Misalinement Detector. 

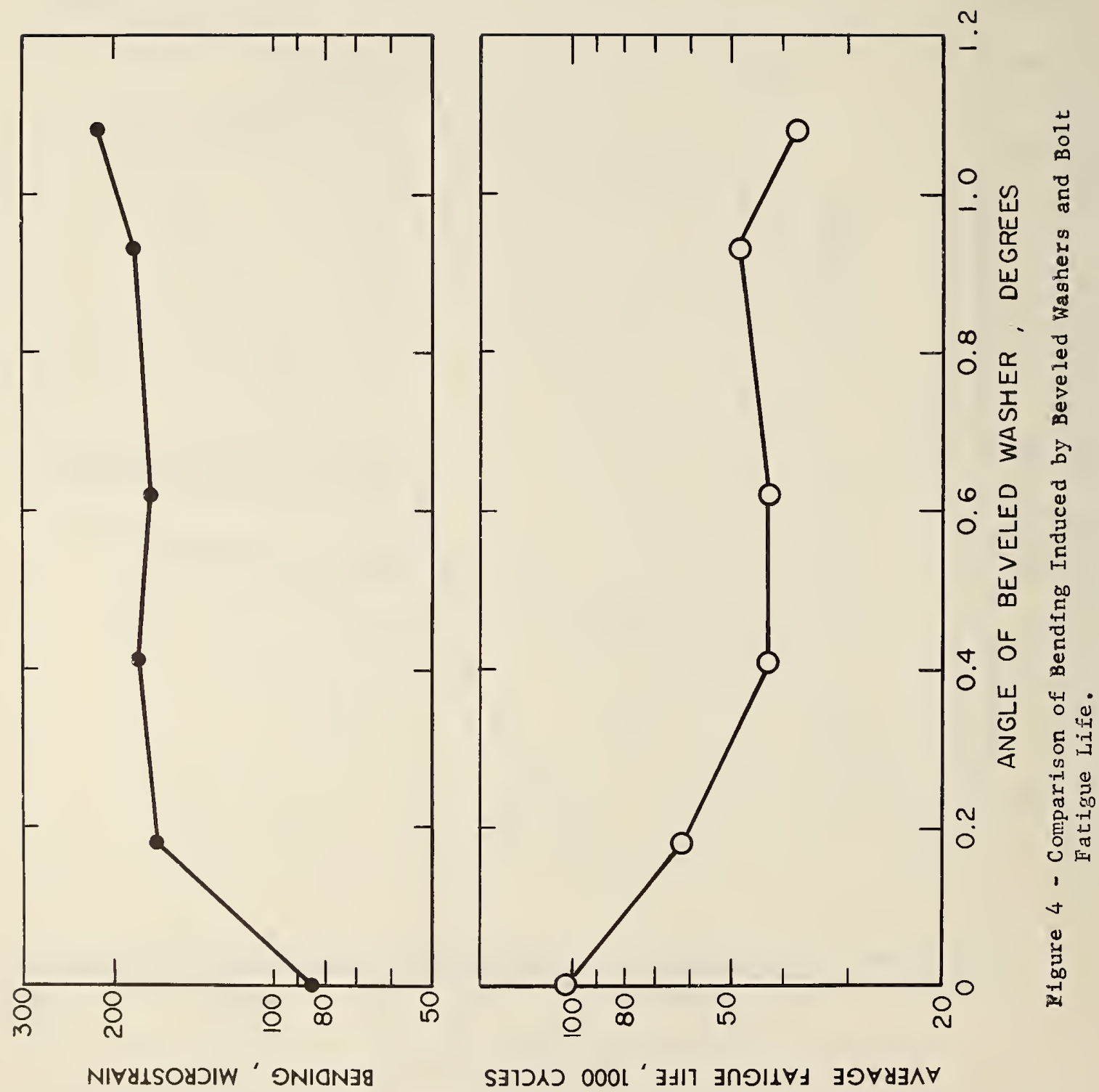

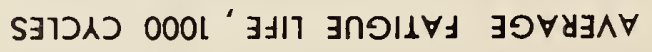




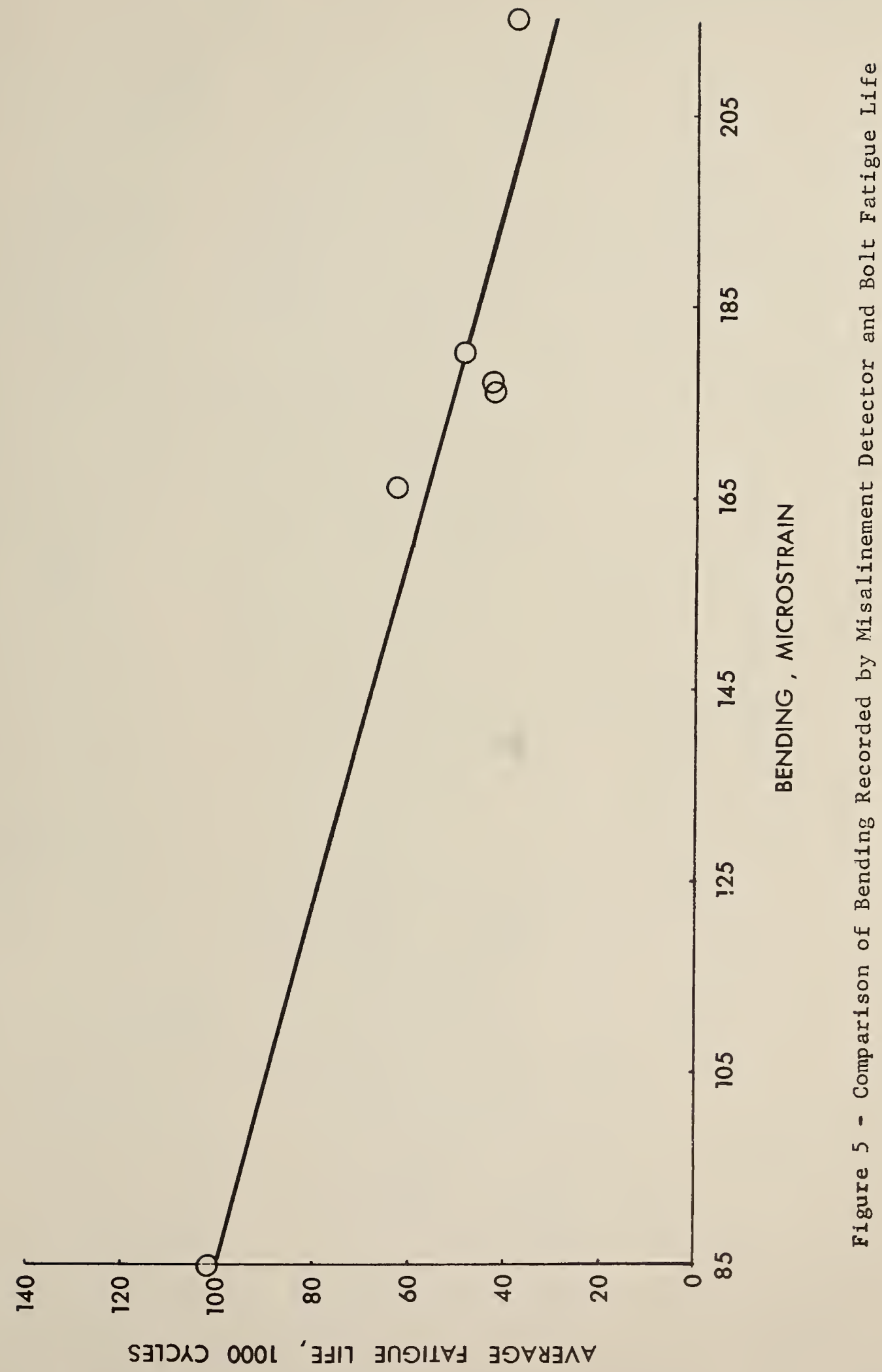





\section{PERIODICALS}

JOURNAL OF RESEARCH reports National Bureau of Standards research and development in physics, mathematics, chemistry, and engineering. Comprehensive scientific papers give complete details of the work, including laboratory data, experimental procedures, and theoretical and mathematical analyses. Illustrated with photographs, drawings, and charts.

Published in three sections, available separately:

\section{- Physics and Chemistry}

Papers of interest primarily to scientists working in these fields. This section covers a broad range of physical and chemical research, with major emphasis on standards of physical measurement, fundamental constants, and properties of matter. Issued six times a year. Annual subscription: Domestic, $\$ 6.00$; foreign, $\$ 7.25^{*}$.

\section{- Mathematical Sciences}

Studies and compilations designed mainly for the mathematician and theoretical physicist. Topics in mathematical statistics, theory of experiment design, numerical analysis, theoretical physics and chemistry, logical design and programming of computers and computer systems. Short numerical tables. Issued quarterly. Annual subscription: Domestic, $\$ 2.25$; foreign, $\$ 2.75^{*}$.

\section{- Engineering and Instrumentation}

Reporting results of interest chiefly to the engineer and the applied scientist. This section includes many of the new developments in instrumentation resulting from the Bureau's work in physical measurement, data processing, and development of test methods. It will also cover some of the work in acoustics, applied mechanics, building research, and cryogenic engineering. Issued quarterly. Annual subscription. Domestic, $\$ 2.75$; foreign, $\$ 3.50 *$.

\section{TECHNICAL NEWS BULLETIN}

The best single source of information concerning the Bureau's research, developmental, cooperative and publication activities, this monthly publication is designed for the industry-oriented individual whose daily work involves intimate contact with science and technology-for engineers, chemists, physicists, research managers, product-development managers, and company executives. Annual subscription: Domestic, $\$ 3.00$; foreign, $\$ 4.00 *$.

- Difference in price is due to extra cost of foreign mailing.

Order NBS publications from:

\section{NONPERIODICALS}

Applied Mathematics Series. tables, manuals, and studies.

Mathematical

Building Science Series. Research results, test methods, and performance criteria of building materials, components, systems, and structures.

Handbooks. Recommended codes of engineering and industrial practice (including safety codes) developed in cooperation with interested industries, professional organizations, and regulatory bodies.

Special Publications. Proceedings of NBS conferences, bibliographies, annual reports, wall charts, pamphlets, etc.

Monographs. Major contributions to the technical literature on various subjects related to the Bureau's scientific and technical activities.

National Standard Reference Data Series. NSRDS provides quantitative data on the physical and chemical properties of materials, compiled from the world's literature and critically evaluated.

Product Standards. Provide requirements for sizes, types, quality and methods for testing various industrial products. These standards are developed cooperatively with interested Government and industry groups and provide the basis for common understanding of product characteristics for both buyers and sellers. Their use is voluntary.

Technical Notes. This series consists of communications and reports (covering both other agency and NBS-sponsored work) of limited or transitory interest.

Federal Information Processing Standards Publications. This series is the official publication within the Federal Government for information on standards adopted and promulgated under the Public Law 89-306, and Bureau of the Budget Circular A-86 entitled, Standardization of Data Elements and Codes in Data Systems.

\section{CLEARINGHOUSE}

The Clearinghouse for Federal Scientific and Technical Information, operated by NBS, supplies unclassified information related to Governmentgenerated science and technology in defense, space, atomic energy, and other national programs. For further information on Clearinghouse services, write:

Clearinghouse

U.S. Department of Commerce Springfield, Virginia 22151 
U.S. DEPARTMENT OF COMMERCE

WASHINGTON, D.C. 20230 